\title{
Resultados de la encuesta a Académicos
}

\author{
Alejandro Treviño-Becerra ${ }^{1}$, Francisco Espinosa-Larrañaga ${ }^{2}$ y Miguel Cruz-López ${ }^{2}$ \\ ${ }^{1}$ Editor; ${ }^{2}$ Coeditor, Gaceta Médica de México
}

\section{Introducción}

Gaceta Médica de México (GMM) es el órgano oficial de divulgación de la Academia Nacional de Medicina de México (ANMM). La ANMM es, a su vez, el órgano consultor del Gobierno Federal en materia de salud. A partir del número 2 del volumen 153, de 2017, se llevó a cabo un cambio de editores responsables de GMM. El objetivo de los nuevos editores es aumentar la calidad de la misma con la publicación de artículos de mayor impacto y reactivar la publicación de los trabajos de los académicos.

El propósito de llevar a cabo una encuesta entre los académicos fue: 1) hacerlos partícipes del diagnóstico de GMM; 2) conocer las debilidades que identifican, así como sus fortalezas; y 3 ) invitarlos a colaborar con propuestas de mejora y publicaciones. Lo anterior, con la finalidad de conocer cómo perciben los académicos la calidad de GMM y cuál es el blanco de lectores a los que va dirigida: ¿académicos?, ¿estudiantes de medicina?, ¿médicos generales?, ¿investigadores? Finalmente se aplicó una encuesta y el objetivo ahora es dar a conocer los resultados de dicha encuesta enviada a los académicos.

\section{Método}

Se elaboró un instrumento tipo encuesta cerrada y abierta, con por 29 preguntas, en las que se exploró: a) la organización editorial de la GMM; b) la participación de los académicos en la GMM; c) la identificación de problemas (debilidades); d) la identificación de fortalezas; y e) las propuestas de mejora y proyección de GMM. El instrumento fue enviado a todos los académicos (muestra censal) mediante la plataforma Survey Monkey; a los correspondientes y honorarios no se les envío. Se utilizó el correo electrónico registrado en los archivos de la ANMM para el envío de la invitación y liga de acceso a Survey Monkey para responder el instrumento. El periodo de acceso y espera de respuestas fue de 3 semanas, con dos avisos de recordatorio antes del cierre. El análisis de los resultados es descriptivo, con valores absolutos y porcentuales.

\section{Resultados}

El instrumento fue enviado a 556 académicos, de los cuales contestaron 235 (el 42\%). Atendieron a la encuesta en proporción semejante ( $47 \%$ cada uno) tantos los académicos titulares como los numerarios. Por departamentos destacó el de Medicina, con 53\% de respondientes. El $66 \%$ de los académicos mencionó que recibe GMM de manera impresa con regularidad, pero solo el $10.5 \%$ de ellos la lee por completo, y definitivamente el $3.5 \%$ no la lee. El $46.6 \%$ de los académicos mencionó que circula GMM en su centro de trabajo.

Con respecto al interés y la experiencia de publicar en GMM, el 58\% de los académicos (136) no ha publicado en GMM en los últimos 5 años. Han publicado poco el $94 \%$ (221), y el $6 \%$ (14) han publicado más de seis artículos. De los que han enviado trabajos para su posible publicación, al 22\% (52) no se les ha

\author{
Correspondencia: \\ Alejandro Treviño-Becerra \\ Unidad de Congresos del Centro \\ Médico Nacional Siglo XXI \\ Bloque B, Avda. Cuauhtémoc, 330 \\ Col. Doctores \\ C.P. 06725, Ciudad de México, México \\ E-mail: atreve16@yahoo.com.mx
}

Fecha de recepción: 08-05-2017

Fecha de aceptación: 09-05-2017

DOI:10.24875/GMM.M17000015
Gac Med Mex. 2017;153:510-513

Contents available at PubMed www.gacetamedicademexico.com 
rechazado su trabajo, mientras que al $78 \%$ (183) sí se les ha rechazado algún trabajo enviado.

En la tabla 1 se pueden ver las fortalezas y las debilidades mencionadas por los académicos.

Con relación a la organización editorial y de sus contenidos, 94 académicos (22.1\%) desconocen cómo está integrado el comité editorial y a 130 (30.5\%) les gustaría pertenecer a dicho comité; los que no están interesados manifiestan que se debe principalmente a falta de tiempo. El 81\% (190) afirma conocer las secciones de GMM. A la pregunta abierta « $i R e-$ comendaría suprimir una o más secciones?», el $60 \%$ (141) recomendaron suprimir las secciones de Casos clínicos e Imágenes en Medicina. Hubo opiniones en contra de la publicación de artículos «simples» de revisión y noticias políticas, y en menores proporciones las secciones de información epidemiológica, biología molecular, e historia y filosofía de la medicina. No hubo sugerencias para incorporar nuevas secciones a la pregunta correspondiente.

Referente a la pregunta «¿Qué cambios propondría para mejorar la calidad de GMM?», destacó la respuesta de que no debe haber cambios en el formato, aunque algunos mencionaron cambios en la portada. El $60 \%$ de los académicos que respondieron la encuesta consideran que la periodicidad de GMM debiera ser mensual y que se incremente el tiro. Con relación a que la publicación se mantenga tanto en papel como en medios electrónicos, la respuesta fue positiva en 202 (86\%) de los 235 académicos que contestaron la encuesta.

A propósito de la distribución, el 43\% (102) pide que la revista se distribuya por mensajería especializada, en segundo lugar que la entrega sea por Servicio Postal Mexicano, y en último, por mensajería propia de la ANMM.

Las preguntas 28 y 29 del instrumento buscaron explorar la utilidad de nuestra revista. Las respuestas más favorables, con un $40 \%$, fueron ser el órgano de difusión de la ANMM y qué lo más importante que GMM ofrece a los médicos no académicos 0 al personal de salud es un apoyo a la educación médica continua mediante la publicación de artículos originales y de revisión y editoriales, principalmente.

En la tabla 2 se pueden ver las respuestas abiertas relacionadas con sugerencias para elevar la calidad de GMM.

En tanto a la pregunta « ¿Piensa usted publicar en GMM en un futuro?», el 66\% (155) de los académicos no tiene pensado enviar un documento a publicar en un futuro. Las respuestas emitidas por los encuestados para tomar la decisión de publicar en lo futuro en GMM se muestran en la tabla 3.

A continuación se transcriben algunas respuestas concretas a la pregunta «¿Qué sugiere para mejorar GMM?», las cuales fueron mencionadas en más de dos ocasiones:

- Promover que los académicos publiquen por lo menos un artículo de investigación clínica o básica original, o bien un artículo de opinión sobre temas controvertidos o de revisión de alto nivel, por lo menos cada 12 a 24 meses.

- Hacer análisis bibliométrico de indicadores de calidad y conocer las citaciones de artículos publicados en GMM.

- Qué la revisión de los artículos sea realizada por académicos expertos en la materia y no solo por los editores.

- El editorial debe basarse en algún artículo original publicado, o haber varios editoriales de artículos que lo merezcan, lo cual da citas a esos artículos.

- Se debe promover la sección Cartas al editor, lo cual da citas a los artículos referidos.

- Es importante incrementar el factor de impacto de la revista, ya que las diferentes instancias evaluadoras, a las cuales tenemos que sujetarnos los investigadores científicos, solo consideran válidas las publicaciones en revistas de alto impacto. El aumentar o disminuir el tiraje de la revista, como se interroga en la pregunta 23 , no impacta sobre la calidad.

Tabla 1. Fortalezas y debilidades de GMM identificadas por los académicos

\begin{tabular}{lc}
\hline Fortalezas & Debilidades \\
\hline - Es percibida como la mejor revista mexicana & - Dudas sobre el proceso de arbitraje editorial \\
- Tiene presencia internacional & - Igual o mayor dificultad para publicar en GMM que en \\
- Está considerada una publicación espléndida e & revistas internacionales de mayor impacto \\
importante & - Retardo en la revisión de artículos enviados y por lo tanto en \\
- Es una revista indexada & la respuesta \\
- Su acceso libre por Internet & - Arbitrajes negativos poco sustentados \\
- Es un vínculo con la comunidad médica en genera. & - Proceso para publicar largo, complejo, confuso y penoso \\
\hline Fuente: encuesta realizada a los académicos, marzo de 2017. &
\end{tabular}


Tabla 2. Respuestas abiertas con sugerencias para mejorar la calidad de GMM

\begin{tabular}{l}
\hline Principales y más frecuentes sugerencias para mejorar: \\
\hline - Publicarla en inglés \\
- Mejor y mayor difusión \\
- Publicación rápida de artículos aceptados, y sin demora \\
- Integrarla a un mayor número de índices internacionales \\
- Incorporar una sección de opiniones libres de los académicos, \\
incluyendo noticias, cartas al editor y artículos de reflexión \\
- Elevar el factor de impacto y hacer un análisis bibliométrico \\
\hline Fuente: encuesta realizada a los académicos, marzo de 2017.
\end{tabular}

Tabla 3. Respuestas emitidas por los encuestados para tomar la decisión de publicar en GMM en el futuro

\begin{tabular}{cc}
\hline $\begin{array}{l}\text { ¿Por qué enviar una } \\
\text { nueva aportación? }\end{array}$ & $\begin{array}{l}\text { ¿Por qué no enviar una nueva } \\
\text { aportación? }\end{array}$ \\
\hline - Dar a conocer & - Bajo factor de impacto \\
resultados de & - La revisión tarda demasiado \\
población mexicana & - Alto grado de dificultad en la \\
- Envío de simposios & respuesta de los revisores \\
cuya publicación no & - Rechazo de trabajos después \\
es frecuente & de larga espera y que \\
& posteriormente son aceptados \\
& en revistas con mayor impacto \\
\hline
\end{tabular}

Fuente: encuesta realizada a los académicos, marzo de 2017.

- El proceso de envío de los artículos para su revisión tiene grandes problemas en su operación; debe realizarse en México y no en España.

- En los últimos años, la GMM ha mostrado una tendencia a publicar artículos «coloquiales» que no aportan al conocimiento de los médicos del primer nivel de atención, y tampoco a la política pública.

- En relación con la educación continua de los médicos de primer contacto, ver el ejemplo de Lancet, JAMA o BMJ, cuyos principales lectores son los médicos de primer contacto, ya que estas revistas se han posicionado como los referentes para la actualización de este personal de salud, contrario a lo que hace GMM.

- Considerando que la ANMM es un órgano asesor del Gobierno para las políticas públicas, GMM debería orientarse hacia cubrir ese fin.

- Realizar una mejor selección de los artículos de investigación originales y desarrollar una sección de actualización clínica para médicos generales, que favorezca la calidad de la atención de la población usuaria de los servicios del primer nivel de atención.

- Hacer más amigable la página electrónica con un link a la revista.

- De acuerdo con el factor de impacto actual de la revista (0.312), ser más permisivos para la publicación de artículos que sorprendentemente son rechazados y luego aceptados en revistas de mayor impacto.

- Que esté en tiempo y forma la edición electrónica.

- Migrar a la publicación de artículos en inglés, dejando la opción en español en línea.

- Hacer más eficiente el manejo editorial de la revista, incluyendo el envío de artículos a revisión mediante una plataforma más amigable.

\section{Discusión}

Las respuestas de los 235 académicos al instrumento la consideramos como una muestra representativa de sus miembros. Posterior al cierre de la recepción de respuestas, se pudo identificar que muchos de los académicos no recibieron la invitación ni la encuesta debido a que no se encontraba actualizada su dirección electrónica.

El 96.5\% de los académicos que respondieron lee por completo o parcialmente GMM, lo que nos indica interés por su parte hacia GMM, y casi la mitad de ellos la recicla en su centro de trabajo, lo que incrementa el número de lectores, que está estimado en cinco lectores más por cada académico que la comparte en su ámbito laboral.

Para que GMM aumente su tiraje y su periodicidad, y se distribuya por mensajería especializada, tendría que tener más recursos económicos y humanos, los cuales se tendrían que generar de la propia revista. Incrementar el tiro, publicarla con periodicidad mensual y distribuirla por mensajería privada implica contar con mayores recursos económicos. La ANMM actualmente no puede financiar esta propuesta debido a lo limitado de sus ingresos. Por otra parte, GMM no tiene entre sus funciones la de conseguir dicho financiamiento, ya que al tener acceso libre por Internet no existe demanda de subscripciones. Principios éticos en el financiamiento, tampoco permiten el uso de publicidad. Si aumenta su calidad, se logrará un más expedito y simple sistema de valoración por pares, e incluso tener anunciantes se convertiría en una fuente de ingresos para la ANMM.

Llama la atención la propuesta de publicar GMM en inglés para mejorar su calidad, ya que el idioma en que está escrito un documento no mejora la calidad del mismo. Sin embargo, reconocemos que al publicarse en inglés puede atraer a autores de otros países y con ello la posibilidad de escritos de mejor calidad. 
Como parte de un proceso de evaluación y seguimiento de GMM, la propuesta de realizar un estudio bibliométrico nos permitiría contar con datos duros sobre su evolución y visualizar los cambios necesarios para elevar su calidad.

Llama la atención que la mayoría de los académicos encuestados (94\%) ha publicado poco en GMM a pesar de ser su órgano oficial de divulgación, y no mencionan como causa que al $78 \%$ de ellos se le ha rechazado algún trabajo enviado.

Los académicos identifican, dentro de las fortalezas que tiene GMM, que es una publicación indexada, con acceso libre mediante Internet, con relevancia internacional y como un vínculo entre la ANMM y la comunidad médica nacional en general. Hechos que son indudables, reconociendo la dificultad que sería medir la vinculación.

Por otro lado, las debilidades podemos resumirlas en tardanza y duda sobre la revisión técnica por pares y una plataforma poco amigable. Ambas situaciones influyen también para que los académicos no tengan la intención en un futuro de enviar trabajos para su publicación a GMM.

Con relación a sí tienen pensado publicar los académicos próximamente en GMM, dos de sus fortalezas son expresadas como motivo para publicar: dar a conocer información de la población mexicana, lo cual consideramos importante, y que GMM es un buen instrumento de educación médica continua a través de la publicación de sus simposios. Por el contrario, razones que inhiben a los académicos a publicar son las principales debilidades de GMM identificadas por los académicos: bajo factor de impacto, tardanza en el proceso de arbitraje y publicación, dificultad para entender la solicitud de los revisores, y poca difusión y distribución.

Al leer las respuestas abiertas destacan dos puntos: 1) la imperiosa necesidad de mejorar el proceso de revisión para no causar desaliento y decepción en los autores por su lentitud, y 2) definir qué tipo de revista debe ser GMM e identificar qué podemos ofrecer a los académicos retirados para que, sí así lo desean, sigan publicando sus experiencias y reflexiones.

La encuesta fue un ejercicio productivo con metodología de punta. Las respuestas muestran interés y compromiso académico que le da vigencia a GMM y a la propia ANM, y permite a los editores y a la directiva replantear la conducta a seguir con GMM en nuestros coacadémicos sobre nuestra revista, con la única intención de mejorarla con el esfuerzo de académicos, editores, impresores, traductores, personal técnico, secretarial y de enlace, distribuidores y posibles anunciantes.

Es indudable que las publicaciones periódicas son un instrumento para la educación médica continua de los médicos contemporáneos y una herramienta para la formación de la nueva generación de profesionales de la salud.

\section{Recomendaciones y conclusiones}

Se obtienen de las observaciones y las respuestas a esta encuesta, así como de la experiencia obtenida y vertida por el editor y los coeditores en estos meses, aunada por las observaciones de la Editorial Permanyer y el trabajo de la auxiliar editorial de GMM, los siguientes puntos:

- Los editores debemos conocer y evaluar cada uno de los trabajos que se reciben para, en caso de ser idóneos, enviarlos a los revisores, o por lo contrario rechazarlos con prontitud.

- El número (pool) de revisores debe triplicarse y para ello se requiere invitar a otros no académicos y a jóvenes investigadores.

- Para evitar el rezago, la valoración por pares debe ser en corto plazo y bajo un formato que permita a los autores, a los editores y a los propios revisores identificar fácilmente la aceptación o las modificaciones sugeridas, o los motivos de rechazo, y constatar cuando estos se realizan con prontitud.

- Los lapsos de toma de decisión entre la recepción de los manuscritos y su publicación tienen que acortarse. En total no debemos sobrepasar los 8 meses.

Además, se buscará un sistema de envío de GMM simultáneo a la publicación de los números correspondientes.

Ya como resultado inmediato de la encuesta se eliminan las secciones de Casos clínicos e Imágenes en medicina. Todos los artículos deberán ajustarse fielmente a las instrucciones para los autores, cuya versión modificada queda publicada y vigente a partir de este número 5 de 2017.

\section{Agradecimiento}

Al Lic. Miguel Ángel Vázquez Luna, asesor en Sistemas de la Información de la ANMM, por su colaboración para el envío electrónico de la encuesta y la captura de las respuestas. 